Gut, 1984, 25, 203-205

Clinical trial

\title{
Controlled trial of rifampicin and ethambutol in Crohn's disease
}

\author{
J L SHAFFER, S HUGHES, B D LINAKER, \\ R D BAKER, AND L A TURNBERG
}

From the Department of Medicine, Hope Hospital (University of Manchester School of Medicine), Salford, and Computer Laboratory, Salford University, Salford

SUMmaRY We pursued the possibility that Mycobacterium kansasii might be an aetiological agent in Crohn's disease by carrying out a trial of treatment with antimycobacterial drugs. Twenty seven patients with Crohn's disease took part in a two year randomised double blind, crossover, controlled trial of rifampicin plus ethambutol against placebo. Fourteen patients completed the trial; four required an operation; five were withdrawn as poor compliers, and four because of adverse effects. There was no significant difference in response to the active drugs compared with placebo when expressed in terms of a Crohn's disease activity index or any clinical indicator of disease activity. There was no suggestion that any subgroup of patients - for example, different regions of bowel affected or previous operation - were favourably affected by the drugs. There was no consistent pattern of change in prednisolone requirements although eight patients on long term sulphasalazine had a significant reduction in their plasma sulphapyridine concentrations during the active treatment period. A significant reduction in total white blood count and an increase in plasma ALT were seen during active therapy. The results of the study do not suggest that rifampicin and ethambutol have a role to play in the treatment of Crohn's disease.

Recent efforts to implicate a cell wall deficient mycobacterium in the aetiology of Crohn's disease have yielded a strain of Mycobacterium kansasii cultured from lymph nodes of patients with the disease. ${ }^{1}$ Other groups have also suggested that a transmissable factor may be involved. ${ }^{2-4}$

The $M$ kansasii isolated has been shown to be sensitive in vitro to rifampicin, ethambutol, and ethionomide, but resistant to streptomycin, isoniazid, and sodium amino salicylate. ${ }^{7} \mathrm{We}$ instituted therefore a controlled trial of rifampicin and ethambutol in a group of patients with Crohn's disease.

\section{Methods}

\section{PATIENTS}

Twenty seven outpatients with Crohn's disease entered the trial. The diagnosis was established on clinical, radiological, and histological grounds.

Address for correspondence: Dr J L Shaffer, Dept of Medicine, Hope Hopital, Eccles Old Road, Salford M6 8HD.

Received for publication 6 May 1983
There were 13 women and 14 men, age range $22-50$ years (mean 34.3 years), with a mean duration of disease of 7.4 years (range 0.5-37 years). Seven of the patients had disease apparently confined to the colon, three patients had small bowel disease, and 17 had both small and large bowel disease. Eleven of the patients had had previous operations (10 right hemicolectomy, one jejunectomy). One patient had chronic perianal disease but none had enteric fistulae or abscesses at the start of the trial. Nineteen patients were taking sulphasalazine and eight patients prednisolone.

The trial format was as follows: on the first visit patients were assessed, the purpose of the trial explained and informed consent obtained. One month later, on the second visit, patients were randomly allocated to either ethambutol $(15 \mathrm{mg} / \mathrm{kg} /$ day) plus rifampicin $(10 \mathrm{mg} / \mathrm{kg} / \mathrm{day})$ or to two corresponding placebo tablets by the pharmacy department using a random numbers code. Other therapy was continued as clinically indicated. Patients were reviewed at four weekly intervals and after a full clinical assessment a blood count, ESR, 
and a biochemical profile were measured. At three monthly intervals serum iron, folate, $B_{12}$, magnesium, zinc, copper, and immunoglobulins were estimated. After 12 months the patients were changed over to the alternative treatment period which was continued for a further 12 months.

In order to detect ethambutol induced retinitis, visual acuity and colour discrimination were assessed at each monthly visit and, initially, monthly and then three monthly, visual evoked responses were recorded. Patient compliance was assessed by a tablet count and spot urine checks for rifampicin induced changes in urine colour.

Withdrawal from the trial occurred because of poor compliance, adverse effects, or surgical resection of diseased bowel. Disease progress was assessed clinically and by standard laboratory tests enabling us to calculate a 'National Co-operative Crohn's Disease Activity Index' (NCCDAI) 5 after each visit.

The trial was approved by the Salford Health Authority Ethical Committee and informed consent was obtained from each patient.

\section{Results}

Fourteen patients completed the two year trial. Details of the 13 withdrawals are shown in the Table. Four patients developed severe symptoms which required surgical intervention during the trial. Three of these were taking the active drugs and one the placebo. Only one of these four patients was on steroids. She gradually deteriorated during the active period and her prednisolone requirements doubled to $20 \mathrm{mg}$. The other three patients also required surgery for unremitting symptoms. Four patients developed side effects of the treatment (see below). Four patients failed to take their drugs

Table Withdrawals

\begin{tabular}{rllrll}
\hline No & Age & Sex & $\begin{array}{c}\text { Time in } \\
\text { trial } \\
\text { (months) }\end{array}$ & $\begin{array}{l}\text { First year } \\
\text { activel } \\
\text { placebo }\end{array}$ & Reason \\
\hline 1 & 29 & F & 14 & Active & Emigrated \\
2 & 19 & M & 2 & Placebo & Poor compliance \\
3 & 25 & F & 21 & Placebo & Operation \\
4 & 22 & F & 5 & Active & Operation \\
5 & 44 & M & $12 \cdot 5$ & Placebo & Adverse effects \\
6 & 46 & F & $0 \cdot 1$ & Active & Adverse effects \\
7 & 44 & M & 8 & Placebo & Adverse effects \\
8 & 23 & F & 12 & Placebo & Poor compliance \\
9 & 50 & M & 2 & Active & Adverse effects \\
10 & 34 & M & 18 & Placebo & Poor compliance \\
11 & 42 & F & 3 & Active & Operation \\
12 & 29 & F & 6 & Placebo & Operation \\
13 & 58 & F & 2 & Placebo & Poor compliance \\
\hline
\end{tabular}

consistently and one emigrated. Further analysis has been confined to those who completed the trial. Ten patients had relapses as defined by at least one of the following: a rise in their NCCDAI score of $>50$ points, an initiation or increase of prednisolone therapy of at least $10 \mathrm{mg} /$ day, or hospital admission for symptomatic relief. Four of these relapses occurred during the active period, two during placebo, and four patients relapsed once in each treatment period. The mean NCCDAI at the trial start was $210 \pm 37$ (mean \pm SEM), $156 \pm 15$ during the one year placebo period, and $183 \pm 20$ during the active period. These differences are not statistically significant.

There were two admissions, one in each treatment period. Admission criteria were the same as for the other Crohn's disease patients in the routine outpatient clinic.

A clinical assessment made by both the clinicians and the patients at each monthly interval did not differ significantly between the two treatment periods. Eight patients expressed a preference, all saying they felt worse during the active treatment period.

VISUAL EVOKED RESPONSES

No patients showed any clinical evidence of a retinitis and although some patients' visual evoked responses were intermittently above the normal range the mean responses were similar during the two treatment periods (mean $\mathrm{R}$ eye: placebo $108 \cdot 76 \pm 5 \cdot 6 \mathrm{SD}$, active $108 \cdot 46 \pm 4 \cdot 06 \mathrm{SD})$.

\section{BIOCHEMISTRY AND HAEMATOLOGY}

Active therapy reduced the total white blood count from a mean value of $8.3 \times 10^{9} / 1$ in placebo to $7 \cdot 1 \times 10^{9} / 1(p<0.03)$ and a rise in the plasma AST from a mean of $15.5 \mathrm{IU} / 1$ (placebo) to $36.5 \mathrm{IU} / \mathrm{l}$ (active) $(\mathrm{p}<0.03)$. This latter change was associated with initiation of rifampicin therapy and in all cases had settled within three months. A rise in ESR from 16 to $22 \mathrm{~mm} / \mathrm{h}$ in the active treatment period was not statistically significant.

\section{PREDNISOLONE}

At the trial onset 10 patients were on prednisolone (mean dose $8.2 \mathrm{mg}$, range $2.5-30 \mathrm{mg}$ ). Throughout the trial the mean dose did not change significantly (placebo period $6.0 \mathrm{mg}$, active $5.8 \mathrm{mg}$ ). The one patient who came to surgery on steroids may well have had her steroid requirements increased in response to a possible enzyme induction by rifampicin. ${ }^{6}$ This pattern was not observed in any other patient. During the two year period six patients were weaned off their steroids all within the first 12 months of the trial (five on placebo, one on 
active). Three patients had prednisolone therapy initiated (two on active, one placebo) and three required prednisolone at the same dosage throughout.

\section{SULPHASALAZINE}

Nineteen of the 27 patients entering the trial and 10 of the 14 who completed the two year period were on sulphasalazine $1.5-4 \mathrm{~g} /$ day. Individual doses did not change during the trial. Plasma sulphapyridine concentrations during the active period were lower than during placebo $(15 \cdot 29 \pm 0.3 \mu \mathrm{g} / \mathrm{ml}$ placebo; $6.5 \pm 0.67 \mu \mathrm{g} / \mathrm{ml}$ active, $\mathrm{p}<0.02)$ and acetylated sulphapyridine concentrations fell by a similar proportion from $4.41 \pm 3.5 \mu \mathrm{g} / \mathrm{ml}$ placebo; to $1.97 \pm 1.7 \mu \mathrm{g} / \mathrm{ml}$ active; the ratio of acetylated to total sulphapyridine remained unchanged $(0 \cdot 29)$.

\section{ADVERSE EFFECTS}

No serious adverse effects were seen but four patients withdrew because of a syndrome of lethargy, nausea, and vague ill health. Three of the patients were on active therapy and one on placebo at the time of withdrawal. Three other patients had this syndrome on active therapy but were able to continue the trial. In all cases the symptoms started within seven days of treatment and in those who continued had resolved within two months. None of these patients was on steroids at the time of withdrawal. The patient who had adverse effects on placebo had persistent symptoms for eight months before withdrawing followed by a rapid return to normal health.

\section{Discussion}

The growth of a cell wall deficient mycobacterium (M kansasii) after several months of culture of lymph node extracts, from some patients with Crohn's disease, suggested that it may be aetiologically involved. ${ }^{1}$ This organism was sensitive to rifampicin and ethambutol and hence we felt that a trial of therapy with these agents was justified. Subsequently the results of a trial of antimicrobial therapy with sulphadoxine-pyrimethamine which was shown to be ineffective have been reported. ${ }^{7}$ Our longer term trial too showed that drugs to which mycobacterium is sensitive were ineffective in altering the course of Crohn's disease. Although there were relatively few patients treated in our trial it is likely, if the disease was caused by infection with this organism, that a 12 months' course of effective treatment would have produced an obvious improvement and probable cure. That is, we were not expecting this type of therapy to produce a subtle improvement such as might be achieved with immunosuppressive drugs, and which would only be detectable by studying large numbers of subjects for long periods of time. Rifampicin and ethambutol failed to influence favourably either any clinical indicator of disease activity or the calculated Crohn's disease activity index. Furthermore, five out of 10 relapses occurred in patients taking the 'active' drugs and three more patients required an operation during that treatment period. There was no suggestion from their requirement for prednisolone that treated patients were being 'cured' of their disease. We conclude from this analysis that rifampicin and ethambutol have no place in the treatment of Crohn's disease and that it is unlikely that $M$ kansasii is aetiologically significant.

It is of interest that sulphasalazine kinetics were disturbed during the drug treatment period. Reduced plasma concentrations of sulphapyridine were probably caused by an impaired splitting of the diazo bond of sulphasalazine by colonic bacteria consequent upon an antibiotic induced change in bacterial flora. ${ }^{8}$ The slight worsening of the disease activity index and the rise in ESR during this period may have followed the reduced availability of the active moiety, 5 ASA, of sulphasalazine.

\section{References}

1 Burnham WR, Lennard-Jones JE, Stanford TL, Bird RG. Mycobacteria as a possible cause of inflammatory bowel disease. Lancet 1978; 2: 693-6.

2 Mitchell DN, Rees RJW. Sarcoidosis and Crohn's disease. Proc Roy Soc Med 1971; 64: 944-5.

3 Cave DR, Mitchell DN, Kane SP, Brooke BN. Further animal evidence of a transmissable agent in Crohn's disease. Lancet 1973; 2: 1120-2.

4 Donelly BJ, Delaney PV, Healy TM. Evidence for a transmissable factor in Crohn's disease. Gut 1977; 18: 360-3.

5 Best WR, Becktel JM, Singleton JW, Kern F. Development of a Crohn's disease activity index. Gastroenterology 1976; 70: 439-44.

6 Hendrickse W, McKiernan J, Pickup ME, Lowe J. Rifampicin-induced non-responsiveness to corticosteroid treatment in nephrotic syndrome. $\mathrm{Br}$ Med $\mathrm{J}$ 1979; 1: 306.

7 Elliot PR, Burnham WR, Berghouse LM, LennardJones JE, Langman MJS. Sulphadoxinepyrimethamine therapy in Crohn's disease. Digestion 1982; 23: 132-4.

8 Houston JB, Day J, Walker J. Azo reduction of sulphasalazine in healthy volunteers. $\mathrm{Br} J$ Clin Pharmacol 1982; 14: 395-8. 